\author{
Л. В. Балашова \\ Саратовский госуниверситет \\ (Россия, Саратов) \\ balashova53@yandex.ru
}

\title{
КОНЦЕПТУАЛЬНАЯ МЕТАФОРИЧЕСКАЯ МОДЕЛЬ: СЛОВООБРАЗОВАТЕЛЬНЫЙ И ГРАММАТИЧЕСКИЙ АСПЕКТЫ
}

В статье дается диахроническая характеристика метафорической подсистемы, формируемой на базе пространственной модальной модели (в широком ее понимании), в словообразовательном и грамматическом аспектах. Автор выявляет структуру данной модели, устанавливает концептуальное наполнение базовых дифференциальных компонентов членов метафорического поля, а также сопоставляет лексические средства реализации модели в древнерусском и современном русском языке. Синхронно-диахронический анализ указанных средств убедительно доказывает, что на протяжении всего исторического периода развития русского языка формирование однотипных переносов у членов одного семантической сферы носит системный, но избирательный характер. Значительную роль в данном процессе играют такие признаки, как частеречная принадлежность лексемы, тип ее морфемной и словообразовательной структуры. Системно-моделируемый характер формирования и развития модального метафорического поля проявляется в нескольких аспектах. В частности, уже в древнерусском языке наиболее регулярно в процесс метафоризации в рамках данной модели включаются глагольные словообразовательные гнезда, члены которых (за счет соответствующей словообразовательной и морфемной структуры) способны выразить максимальное число предусматриваемых моделью ситуаций. В ходе исторического развития обнаруживается тенденция к усилению системности в выражении конкретного типа метафорических значений в рамках членов одного гнезда. Это проявляется в утрате семантически дублетных вариантов, в вовлечении в метафоризацию новых дериватов, сформированных по образцу действующих семантико-словообразовательных моделей. Этот процесс охватывает в первую очередь ядерные глагольные гнезда, но может распространяться на другие гнезда в рамках одной семантической группы. Наряду с этим действует противоположная тенденция: на разных этапах развития в метафорической подсистеме могут формироваться новые семантически дублетные варианты. Но данный процесс обычно присущ периферийным, малочисленным 
в рамках метафорического поля гнездам, а дублетные формы не отмечены стабильностью во времени.

Ключевые слова: метафора, концептуальная модель, словообразовательное гнездо, пространственная модальная подсистема, диахрония.

Метафорическая концептуализация, как известно, «состоит в осмыслении и переживании явлений одного рода в терминах явлений другого рода» [Лакофф, Джонсон 2004: 389]. Данные модели представляют собой инвариантные структуры, объективированные в культуре этноса и определяющие картину мира [Арутюнова 1998; Баранов 2014; Блэк 1990; Минский 1988]. Такой подход обусловливает потенциальное включение в метафоризацию слов из одной семантической сферы, поля и группы. Но, как показывает анализ конкретных концептуальных моделей, сам процесс формирования однотипных переносов достаточно избирательный, причем не последнюю роль в этом играют такие характеристики, как частеречная принадлежность лексемы, ее грамматические признаки, тип морфологической и словообразовательной структуры. Более того, и в синхронии, и в диахронии вовлечение в метафоризацию различных членов сфер, полей и словообразовательных гнезд имеет системно-моделируемый характер [Балашова 2014а; 2014б].

Основные тенденции в развитии русских метафорических подсистем в деривационном аспекте можно проследить на примере одного из самых устойчивых во времени метафорического поля, формируемого на базе пространственной модальной модели - в широком ее понимании, с помощью которой уже в древнерусском языке складывается концепция представлений о деятельности и бездеятельности субъекта, о наличии или отсутствии у него желаний, стремлений и способности добиться цели, о наличии или отсутствии у субъекта свободы воли, а также происходит оценка субъекта и его жизненной позиции, его желаний, стремлений и способов их достижения. Данная концептуальная схема остается продуктивной и в современном русском языке.

Наиболее последовательно данное представление реализуется в языке в виде противопоставления движения и покоя, что непосредственно связано с общей философской концепцией «движение есть жизнь». Соответственно покой воспринимается как отсутствие у субъекта активной жизненной позиции, желаний, стремлений, стимулов для развития (ср.: льнивыл - от лежати 'находиться в лежачем положении'); движение, напротив, ассоциируется с активной, деятельной позицией. В самом противопоставлении таких позиций заложена система оценок, когда «ситуация отсутствия желания у человека воспринимается крайне отрицательно» [Коновалова 1997: 128] (ср.: Есть мечта? Беги к ней! Не получается? Иди к своей мечте. Не можешь идти - ползи. Не можешь ползти? Ляг и лежи в направлении мечты ! (интернет-мем)).

Представление о типе желаний, стремлений, о возможности их реализации осмысляется через противопоставление поступательного и непоступательного движения. 
В частности, ориентированное поступательное движение воспринимается как целенаправленная деятельность, реализация желаний, стремлений, тогда как характер движения уточняет тип волеизъявления:

- Движение к какой-либо точке ассоциируется со стремлением удовлетворить желание, добиться результата (ср.: иди к добродттели не обрацаися къ злобъ. ГБ XIV'; Это путь человека к самому себе, а через какую именно систему верований он придет к изели - неважно, считает Лак Буни. В. Дараган, Б. Каллаев);

- Движение в сторону, от стабильной в пространстве точки осмысляется как активное желание избежать какой-либо ситуации, уклониться от принятия решения, от внешнего воздействия и т. П. (ср.: И гонезнуть укоризны врагъ своихъ. Пал 1406; М. Захарова справедливо назвала убийство посла терактом и пообещзала, что виновные не уйдут от наказания. Д. Орешкин);

- Достижение точки, избранной в качестве ориентира, ассоциируется с успешным решением проблемы, с обретением желаемого (ср.: Да с чистою свъстью х(с)выхъ таинъ доидемъ. Мен. к. XIV; И то была впервые его посетившая ревность к безоглядной стремительности молодого сознания, пришедшего к цели кратчайшим путем. Д. С. Данин);

- Невозможность ориентироваться в пространстве, достичь ориентира, а также непоступательное движение, движение в неверном направлении, мимо цели воспринимается как неспособность добиться результата, реализовать свои желания, как ошибка, заблуждение и т. п. (ср.: Тщзане ваше и вертвнье. с вам в пагубу буди. ПНЧ XIV; Обративыи гръшника от заблужения. ЛИ 1425; Мне давно казалось, что он топчется на месте, в то время как я шаг за шигом неуклонно иду вперед. В. Шефнер; Не только большие, но пятиэтажные буквы надо над Злом и Добром, и чтоб мигали как маяки! А то мы заблудились в нюансах! А. Солженицын).

Особую роль в реализации модели играет траектория движения (движение к цели по прямой, по кругу, зигзагом). С помощью соответствующей лексики дается оценка не только возможности достичь цели, но и самой цели, а также средств ее достижения. Движение по прямой осмысляется как верное направление развития, как истинность, тогда как ломаная или искривленная траектория - свидетельство ложного направления в развитии человека, общества и т. п. (ср.: правыи 'прямой' $\rightarrow$ 'правильный': Слава ти, Хе, иже направи на правыи путь. УспСб ХІІ/ХІІІ; извращение 'поворот, оборот' $\rightarrow$ 'извращение': Подоба же есть намь и еретичьско извращение въдъати. ШестИоЕкз 1263; Верной дорогой идете, товарищи!; Жаждет попасть в «высшее общество» окольными путями (за счет выгодной женитьбы), не прилагая к этому никаких достойных усилий (выссиее образование, хотя бы, стремление к самообразованию, самосовершенствованию... Коллективный. Форум: Москва слезам не верит; 2011).

1 Здесь и далее древнерусские источники даются в сокращениях, принятых в лексикографических источниках. 
В соответствии с основной концепцией различного рода преграды, большое расстояние до цели и плохое качество дороги воспринимаются как помеха в достижении цели, в исполнении желаний или как нечто, что ведет к ошибке, к результату, обратному желаемому. Напротив, средства, способствующие быстрому и беспрепятственному перемещению в заданном направлении, ассоциируются с условиями, облегчающими решение поставленной задачи (ср.: прғпутие 'прегра-

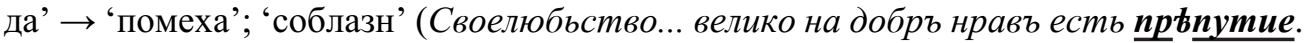
ГБ ХІ; Но путь к этому успеху ещзе далек и обещчает быть полон ухабов и рымвин. А. Бухбиндер).

Уже в древнерусском языке складывается достаточно четкая система репрезентации волеизъявления через каузативное осмысление ситуации: активизация движения объекта, его перемещение или удержание осмысляются как активное волевое воздействие на другое лицо, на развитие событий в нужном субъекту направлении, тогда как объект в данной ситуации ассоциируется с безвольной личностью, зависящей от внешних обстоятельств и других людей (ср.: Дьяволь не может члвка от добра дъла къ злу волочи. ЗЦ XIV; Генштаб направил в Кремль документ, надеясь подтолкнуть Ельцинна к принятию решения по этой проблеме. В. Баранец).

Характерная особенность модели - ее способность выражать модальные значения в рамках разных смысловых сфер (интеллектуальная, эмоциональная, социальная деятельность человека, социально-политическая, идеологическая жизнь социума и др. Если субъектом действия в метафорически осмысленной ситуации является не человек, а мысль, эмоция, социальный, идеологический феномен и т. п., то этот феномен персонифицируется, обретая черты самостоятельной личности (ср.: тенвта бо и съти суть мирьскыхъ бесъды... и словесы въ блудъ заведуть. ПНЧ XIV; По-прежнему пробуксовывает «нормандская четверка», по-прежнему ничего не достигнуто на карабахском направлении. А. Полунин; Беловежский сговор толкнул страну на путь деградаџии экономики и социиальной сферы. Г. Зюганов).

Безусловно, названные варианты реализации пространственной модальной модели не исчерпывают всех возможных аспектов данной концептуальной сетки. Но принципиально значимым можно считать то, что данная модель устойчиво и системно функционирует уже в памятниках XI-XIV вв.

В частности, уже в древнерусском языке наиболее последовательно в процесс метафоризации этого типа включаются глаголы поступательного и непоступательного движения. Это вполне закономерно, поскольку именно предикаты дают обобщенную характеристику одной ситуации сквозь призму другой (ср.: бъжати, блудити, двигати, рискати, ступати, скакати, ити, гънати, гоньзну$m u)$. Не менее системно значимым оказывается тот факт, что практически каждый из этих и других глаголов имеет большое число дериватов (глагольных и именных), которые (за счет соответствующей словообразовательной и морфемной структуры) способны выразить максимальное число предусматриваемых моделью ситуаций; ср.: 
- бъжати - более 40 единиц: бъгливыи, бъгание, бъгунъ, бъгльиь, бъгание, възбъгнути, избъгнути, избъжание, отъбъгати, отъбъгательныи, отъбъгание, отъбъжение, побъгнути, подъбъгати, прибъгнути, прибъжище, прибъчи, пробъгати, пръбъгати, првбъгание, убъгати, убъжьныи;

- блудити - около 30 единиц: блудъ, блудьникъ, блужение, блудьныи, заблудити, заблужение, заблудьникъ, незаблудьныи, приблудити, првблудити, прьблудьство, съблудити;

вести / водити - более 60 единиц: водитель, вожь, водьць, вождевица, вожествие, въвести, въвестися, въведение, въводити, въвожии, възвести, довести, завести, заводити, изводити, изводьство, навести, наводъ, отъвести, повести, повестися, повожение, привести, подъвести, провести, проводьникъ, првдъвестися.

Характерной особенностью метафорической подсистемы является включение в ее состав частичных, односторонних словообразовательных (по В. Г. Гаку) метафор, «когда образование нового значения связано с морфологическим изменением слова, с добавлением аффиксов к основе, используемой в переносном значении» (ср.: сердиевина) [Гак 1988: 13-14]. Примечательно, что наиболее регулярно первичные модальные ЛСВ по концептуальному образцу переносных формируются у слов со сложной морфемной структурой (ср.: отъбъжанье 'намеренное уклонение, воздержание, избавление от чего-л.'; незаблудьно 'безошибочно').

Как отмечалось, в диахронии пространственная модальная модель сохраняется фактически без изменений. Весьма стабильной во времени является также система средств выражения этих значений. Так, на протяжении всего исторического периода развития русского языка активно используются в переносных значениях многие гнезда с глагольной вершиной, характеризующей поступательное и непоступательное движение, перемещение и насильственное удержание объекта (ср.: идти, бежать, вести, вертеть, плутать, влечь, гнаться, ловить, держать и др.). Ядерные из этих словообразовательных гнезд (СОГ) по-прежнему представлены в составе метафорической подсистемы десятками единиц (ср.: СОГ бежать - около 40 слов; вести - около 40 слов; влечь - более 30). Вместе с тем в ходе исторического развития наблюдаются существенные изменения в составе метафоризуемых семантических групп и СОГ. Есть также изменения в самой системе средств выражения конкретных значений. Причин подобных изменений несколько.

Во-первых, внутри гнезд, устойчиво функционирующих в составе этого метафорической подсистемы в диахронии, наблюдается утрата семантически дублетных однокоренных слов и появление новых единиц, сформированных по образцу действующих словообразовательных моделей. Следовательно, усиливается системность внутри СОГ в выражении конкретного типа метафорических значений. Например, в СОГ бъжати утрачиваются семантически дублетные члены со значением 'уклоняться / уклониться от чего-л.'” възбъжати, възбъгнути, отъбъгати, отъбъгивати, отбъчи, пробъгнути, пробъгати, пръбъгати. Новые члены данного гнезда расширяют семантические возможности в выражении различных видов модальности за счет соответствующей словообразовательной структуры дериватов; например, разбежсаться ‘начать действовать в полную силу'. Однако этот процесс 
не идет прямолинейно: на разных этапах развития русского языка в метафорическую подсистему могут включаться новые семантические однокоренные дублеты, которые, впрочем, обычно не слишком стабильны в диахронии. Так, в текстах XVI-XVII вв. фиксируются бъгивати, забежати, объгати в значении 'уклоняться / уклониться'; подбъгати 'обращаться за помощью'.

Процесс упорядочения средств выражения одного типа значений может охватывать целые СОГ в рамках одной семантической парадигмы. Так, среди глаголов и их дериватов, характеризующих в первичных ЛСВ движение с большой скоростью, в метафорической подсистеме закрепляются члены гнезда бъжати, а гнездо гоньзнути (гоньзнути, гоньзнутися, гонезение, гонезати, гонезти, гонзити, угоньзноути), полностью утрачивается (ср. в древнерусском языке: Ащ, хощеши мукы гознути. то никого же не оклеветаи. ИлПосл ХІ).

Наиболее нестабильны во времени периферийные члены внутри одного гнезда или одной семантической парадигмы. Их периферийность проявляется в том, что, как правило, и в древнерусском языке в процесс метафоризации вовлекаются единичные члены этих СОГ; например: крянути 'сдвинуть' (Добляго не може крянути с вьры. Изм XIV*); пругло 'сеть' (Окрили и от всьхъ пругль неприязнинъ. СлВарл XII); прудъ 'поток' $\rightarrow$ 'стремление' (Обрете въздание подвигомъ и прудо$\underline{\text { мъ }}$ твоимъ. Мин 1096). Многие из утраченных членов принадлежат к церковнославянской лексике. Однако их неустойчивость в диахронии не может быть связана только с этим (ср. сохранение в современном русском языке в качестве ядерных именно славянизмов: в СОГ бежать - избежать, избегать, во избежание; в СОГ влечь - влечь, влечение, вовлечь, навлечь, отвлечь, повлечь, привлечь, увлечь, увлечение; в СОГ достигать - достигать, достижение, достижимый, недостижимый). Утрата одних и укрепление других членов метафорического поля связаны с целым комплексов факторов. Важно то, что в результате этих процессов всегда усиливается системность в выражении определенного типа значений, хотя следует отметить, что выбор старославянского варианта в качестве основного часто сопровождается утратой образности, впрочем, подобный процесс может распространяться и на исконно русские варианты (ср.: избежать, стремление).

Во-вторых, усиление системности в выражении конкретных типов значений с помощью определенных единиц пространственной лексики происходит не только на уровне СОГ, но и на уровне целых семантических групп. Ее проявлением может служить значительное увеличение (при достаточной структурированности системы значений и средств их выражения) состава ядерных групп.

Например, в диахронии продуктивностью отмечены переносы по схеме: 'двигаться без цели, беспорядочно’ $\rightarrow$ 'совершать неблаговидные поступки; грешить, клеветать', 'ошибаться'. В древнерусском языке большой активностью в формировании таких переносов было отмечено гнездо блудити. В XVI-XVII вв. в процесс метафоризации включается члены гнезда плутати: плуть, плутни, плутовие, плутишко, плоутовство, плутость, плутство, плутскии, плутыга, причем большинство из них относится к частичным метафорам, имеющим в качестве первичного значения 'обман', 'ошибка', 'обманщик' и т. п. Сохраняют свою продуктивность члены 
этого гнезда и в современном русском языке (ср.: плутовка, плутливый, плутливо, плутливость, плутоватьій, плутовато, плутоватость, плутовской, архиплут, наплутовать, переплутовать, сплутовать). Более того, члены этих двух СОГ становятся одним из основных средств выражения данных типов значений (не случайно большинство из них относятся к генетическим метафорам), достаточно четко противопоставляясь по ряду признаков. Невозвратные глаголы СОГ блудить (и производные от них имена) характеризуют недостойное моральное поведение субъекта; возвратные глаголы (и производные имена) акцентируют внимание на ненамеренной ошибке в действиях, поступках субъекта (ср.: заблуждаться, заблуждение), тогда как члены СОГ плутать фиксируют недостойное поведение субъекта, связанное с намеренным введением в заблуждение кого-либо (ср.: плут, плутовать). Процесс этот идет постепенно. Еще в XVIII в. встречаются употребления типа: Но мысль блудящая ['беспокойная’] сон сладкой всколебала. Майков; Блудный ['впадающий в ошибку’] дух, или кто следует какому блуждению. РГЛ: 10.

В целом, наиболее продуктивны в диахронии глаголы, составляющие ядро системы. Однако иногда большей активностью отмечена именно предметная лексика. Так, значительно увеличивает состав та часть метафорического поля, которая характеризует средства, препятствующие достижению цели, реализации стремлений, желаний, причем пополняют эту часть поля лексемы из различных предметных групп. Например, в современном русском языке, наряду с традиционными (преnоны, преграда, препятствие), используются лексемы, характеризующие плохое качество дороги, особенности рельефа, части механизма, выполняющие соответствующую функцию (ср.: ухабы, рогатки, барьеры, puфы, тормоз). И в данном случае активизация процесса наблюдается уже в XVIII в. (ср.: сделать кому по делу загвоздку. САР 2 II), причем иногда в этот период вовлечение новых членов в состав метафорического поля идет даже более регулярно, чем в современном русском языке. (ср.: И торговать в тех городех со всякой повольностию, безо всякой зацепки ['помехи'] и препятия. ПСЗ III). В тот же период в процесс вовлекается лексика из других пластов, в частности, из «культурной», «образовательной» смысловой сферы. Например, значение 'препятствие' развивает существительное запятая 'знак препинания' (ср.: [Востряков:] Пирожки? - Hy! Boт запятая! Которому господину их нести? Левшин). Однако регулярным этот тип переноса не становится, и в дальнейшем ядро парадигмы по-прежнему составляют члены традиционных полей и групп.

Все это свидетельствует о продуктивности самой концептуальной модели и системности средств ее выражения.

Наконец, в диахронии метафорическая подсистема не только пополняется новыми членами, но и утрачивает большое число членов, причем семантически не дублетных. Обычно это лексемы из малочисленных СОГ, которые утрачивают связь с первичным значением. Например, уходят из метафорической подсистемы: быстрити 'побуждать', быстритися 'стремиться к чему-л.'; отъскочити, отъскакати 'уклониться / 'уклоняться’; рискати, изъльзти 'стремиться / устремиться'; пририскати, нальзти 'добиться чего-л.' (ср.: Не напраснымъ же они устремлениемь 
быстрящеся. ВИТ XVII; [Роман] оть враговъ бъгая, и брани отскоча... но ярость восприемъ на агаряны. ЛНик IX; Любо собъ славу нальзу, а любо главу свою положю. ЛР XV; Изльзение ума к надъемому. КрмБ XVI). Но их место в данном случае занимают слова из тех же групп, но с более ощутимой внутренней формой. Следовательно, поддерживается определенное равновесие внутри системы.

Таким образом, исследуемая модель представляет собой постоянно изменяющееся и в силу именно этого «живое», продуктивное средство выражения модальной семантики, причем деривационные процессы играют в этом процессе активную роль. Тем самым еще раз подтверждается взгляд на словообразование как на неотъемлемую честь лексико-семантической системы языка.

\title{
Литература
}

Арутюнова Н. Д. Язык и мир человека. - М.: Языки русской культуры, 1998. $896 \mathrm{c.}$

Балашова Л. В. Русская метафора. Прошлое. Настоящее. Будущее. - М. : Языки славянских культур, 2014a. - 496 с.

Балашова Л. В. Русская метафорическая система в развитии: XI-XXI вв. - М. : Рукописные памятники Древней Руси: Знак, 2014б. — 632 с.

Баранов А. Н. Дескрипторная теория метафоры. - М.: Языки славянской культуры, 2014. - 632 с.

Блэк М. Метафора // Теория метафоры. - М. : Прогресс, 1990. С. 153-172.

Гак В. Г. Метафора: универсальное и специфическое // Метафора в языке и тексте. - М.: Наука, 1988. С. 11-26.

Коновалова Н.Ю. Концептуальное наполнение лексем воля и желание в русском языке // Актуальные проблемы русистики. - Екатеринбург: Изд-во Уральск. ун-та, 1997. С.: 128-130.

Лакофф Дж., Джонсон М. Метафоры, которыми мы живем. - М. : Едиториал УРСС, 2004. - $256 \mathrm{c.}$

Минский М. Остроумие и логика когнитивного бессознательного // Новое в зарубежной лингвистике. Вып. 23. - М. : Прогресс, 1988. С. 281-309.

\author{
L.V. Balashova \\ Saratov State University \\ (Russia, Saratov) \\ balashova53@yandex.ru
}

\section{CONCEPTUAL METAPHORICAL MODEL: WORD-FORMATIVE AND GRAMMATICAL ASPECTS}

The article gives a diachronic characteristic of the metaphoric subsystem formed on the basis of the spatial modal model (in its broad sense), in the derivational and grammatical 
aspects. The author reveals the structure of this model, establishes the conceptual filling of the basic differential components of the members of the metaphorical field, and also compares the lexical means of implementing the model in Old Russian and modern Russian. Synchronous-diachronic analysis of these means convincingly proves that during the entire historical period of the development of the Russian language, the formation of the homotypic hyphenation among the members of one semantic sphere is systemic, but selective. Significant role in this process is played by such signs as the part-of-speech belonging of the lexeme, the type of its morphemic and word-formative structure. The system-modelled nature of the formation and development of the modal metaphorical field is manifested in several aspects. In particular, already in the Old Russian language the verbal word-forming nests are included most regularly in the process of metaphorization within the framework of this model, the members of which (due to the corresponding word-formation and morphemic structure) are able to express the maximum number of situations envisaged by the model. In the course of historical development, there is a tendency to strengthen systematicity in the expression of a specific type of metaphorical meanings within the members of one nest.

This is manifested in the loss of semantic doublets, as well as in drawing new derivatives formed on the basis of existing semantic word-formation models into the process of metaphorization. This process primarily affects nuclear verbal nests, but can extend then to other nests within the same semantic group. Along with this, there is an opposite tendency: at different stages of development, new semantic doublets can be formed in the metaphorical subsystem. But this process is usually characteristic of peripheral nests, that are non-numerous in the metaphorical field, and the doublet forms are not stable in time.

Keywords: metaphor, conceptual model, word-formation nest, spatial modal subsystem, diachrony.

\section{References}

Arutyunova N. D. Yazyk i mir cheloveka [Language and the world of the human]. Moscow, 1998. $896 \mathrm{p}$.

Balashova L.V. Russkaya metaforicheskaya sistema v razvitii: XI-XXI vv. [Russian metaphorical system in development: XI-XXI centuries]. Moscow, 2014. (Studia Philologica).

Balashova L.V. Russkaya metafora. Proshloye. Nastoyashcheye. Budushcheye [Russian metaphor. Past. Present. Future]. Moscow: Yazyki slavyanskikh kul'tur, 2014a. $496 \mathrm{p}$.

Baranov A. N. Deskriptornaya teoriya metafory [Descriptor theory of metaphor]. Moscow: Yazyki slavyanskoy kul'tury, 2014. $632 \mathrm{p}$.

Black M. Metafora [Metaphor]. Teoriya metafory [Theory of metaphor]. Moscow: Progress, 1990, pp. 153-172.

Gak V.G. Metafora: universal'noye i spetsificheskoye [Metaphor: universal and specific]. Metafora vyazyke i tekste [Metaphor in language and text]. Moscow: Nauka, 1988, pp. 11-26. 
Konovalova N. Yu. Kontseptual'noye napolneniye leksem volya i zhelaniye v russkom yazyke [Conceptual filling of lexemes will and desire in Russian]. Aktual'nyye problemy rusistiki [Actual problems of Russian studies]. Yekaterinburg: Izd-vo Ural'sk. un-ta, 1997, pp. 128-130.

Lakoff J., Johnson M. Metafory, kotorymi my zhivem [Metaphors we live by]. Moscow: Yeditorial URSS, 2004. 256 p.

Minsky M. Ostroumiye i logika kognitivnogo bessoznatel'nogo [Wit and its Relation to the Cognitive Unconscious]. Novoye v zarubezhnoy lingvistike. Vyp. 23 [New in foreign linguistics. Issue. 23]. Moscow: Progress, 1988, pp. 281-309. 